\title{
1 Global drivers of diversification in a marine species complex
}

3 Catarina N.S. Silva ${ }^{1}$, Nicholas P. Murphy ${ }^{2}$, James J. Bell ${ }^{3}$, Bridget S. Green ${ }^{4}$, Guy Duhamel ${ }^{5}$, Andrew C.

4 Cockcroft $^{6}$, Cristián E. Hernández ${ }^{7}$, Jan M. Strugnell ${ }^{1,2}$

${ }^{1}$ Centre of Sustainable Tropical Fisheries and Aquaculture, James Cook University, Townsville, Qld 4810,

8 Australia

92 Department of Ecology, Environment \& Evolution, La Trobe University, Melbourne, Vic 3086, Australia

$10{ }^{3}$ School of Biological Sciences, Victoria University of Wellington, Wellington, 6140, New Zealand

$11{ }^{4}$ Institute for Marine and Antarctic Studies, University of Tasmania, Hobart, TAS 7001, Australia

$12{ }^{5}$ Département Adaptations du Vivant, BOREA, MNHN, Paris, 75005, France

$13{ }^{6}$ Department of Agriculture, Forestry and Fisheries, Cape Town, 8012, South Africa

$14{ }^{7}$ Departamento de Zoología, Facultad de Ciencias Naturales y Oceanográficas, Universidad de Concepción, 15 Casilla 160C, Concepción, Chile

\section{Abstract}

19 Investigating historical gene flow in species complexes can indicate how environmental and reproductive barriers shape genome divergence before speciation. The processes influencing species diversification under environmental change remain one of the central focal points of evolutionary biology, particularly for marine organisms with high dispersal potential. We investigated genome-wide divergence, introgression patterns and inferred demographic history between species pairs of all extant rock lobster species (Jasus spp.), a complex with long larval duration, that has populated continental shelf and seamount habitats around the globe at approximately $40^{\circ} \mathrm{S}$. Genetic differentiation patterns revealed the effects of the environment and geographic isolation. Species associated with the same habitat structure (either continental shelf or seamount/island) shared a common ancestry, even though the habitats were not adjacent. Differences in benthic temperature explained a significant proportion (41.3\%) of the genetic differentiation. The Eastern Pacific species pair of $J$. caveorum and $J$. frontalis retained a signal of strict isolation following ancient migration, whereas species pairs from Australia and Africa and seamounts in the Indian and Atlantic oceans included events of introgression after secondary contact. Parameters estimated for time in isolation and gene flow were congruent with genetic differentiation metrics suggesting that the observed differentiation patterns are the product of migration and genetic drift. Our results reveal important effects of habitat and demographic processes on the divergence of species within the genus Jasus providing the first empirical study of genome-wide drivers of diversification that incorporates all extant species in a marine genus with long pelagic larval duration. 


\section{Introduction}

The discrete categorization of speciation modes as sympatric, allopatric or parapatric is now considered to be overly simplistic (Butlin et al. 2008). Several events (or modes of speciation) can influence the biogeographic states of populations at different time periods during divergence, and as a result, the speciation process is now generally considered to be gradual and reticulated (Smadja \& Butlin 2011; Feder et al. 2012). However, the processes responsible for influencing species diversification are still poorly understood and remain one of the central focal points of ecology and evolutionary biology (Arendt et al. 2016).

Reconstructing the diversification history for species complexes can be challenging for non-model marine organisms (e.g. Palero et al. 2009; Momigliano et al. 2017) as many have large population sizes and the potential for long distance dispersal, which frequently result in weak genetic differentiation (Ovenden 2013). For these species, it is often difficult to determine whether weak genetic differentiation is actually present or masked by the large population sizes (Lowe \& Allendorf 2010). In addition, marine species with long distance dispersal can quickly fill available niches, leaving fewer opportunities for in situ cladogenesis (Pinheiro et al. 2017). As a result, only a few studies have reconstructed the history of diversification in marine species (e.g. Crow et al. 2010; Le Moan et al. 2016; Momigliano et al. 2017; Souissi et al. 2018; Titus et al. 2019).

Changes in the distribution of marine species resulting from historical climatic variation have been an important driver of diversification across taxa (Davis et al. 2016). Climatic fluctuations during the late Pleistocene, in particular, resulted in periods of isolation intercalated by contact and gene flow between lineages (Hewitt 2000). These events dramatically transformed available habitat causing major shifts in species distribution ranges and shaping the genetic structure of many marine species worldwide (Benardine Jeffrey et al. 2007; Kenchington et al. 2009; Van Oppen et al. 2011; Strugnell et al. 2012). Sequential glacial and interglacial periods have then further shaped the divergence history of species as a result of periods of isolation intercalated by gene flow (Weigelt et al. 2016). A better understanding of the species-specific historical context of divergence is therefore needed to estimate the actual timing and role of gene flow during speciation. Understanding how historical climatic fluctuations shaped species divergence provides clues on how species might respond to future environmental changes, which is vital for effective conservation and management plans (Olivieri et al. 2016).

Advances in next-generation sequencing (NGS) now provide the opportunity to investigate genomewide patterns of differentiation along the speciation continuum, allowing the better detection of changes as two lineages diverge from one another on the path to reproductive isolation (Feder et al. 2012). In particular, these methods provide effective tools solutions for species with no reference genomes (Catchen et al. 2017), 
integration of genomic and environmental data which can be used for testing the hypothesis that selection is more efficient than drift in opposing the homogenizing effects of migration (Manel \& Holderegger 2013). In addition, this approach can also detect candidate markers underlying adaptation to local environments for species with moderate to long distance dispersal potential (e.g. Benestan et al. 2016; Sandoval-Castillo et al. 2018). This robust approach is particularly useful in the marine environment where isolation and speciation is increasingly found to be associated with selection/local adaptation (Rocha et al. 2005; Momigliano et al. 2017). Improvements in methodology have further enabled the use of genome-wide polymorphism data to infer complex demographic histories and the relative influence of gene flow and historical processes on the genomic landscape. For example, in the marine environment this approach has been used in the European anchovy Engraulis encrasicolus (Le Moan et al. 2016), the Atlantic Salmon Salmo salar (Rougemont \& Bernatchez 2018) and the corkscrew sea anemone Bartholomea annulate (Titus et al. 2019). One increasingly popular approach is demographic inference based on the computation of a joint allele frequency spectrum (JAFS) from genetic polymorphism data (Gutenkunst et al. 2009; Excoffier et al. 2013). This approach allows an estimation of several demographic parameters such as population sizes, migration rates and time intervals since specific events using a composite likelihood. Therefore, the role of historical events in the diversification and speciation of marine species can now be more accurately determined.

Rock lobsters (Jasus spp.) are a useful model to study the role of historical climatic variations and gene flow on divergence. The six extant Jasus lobster species (J. caveorum, J. edwardsii, J. frontalis, J. lalandii, J. paulensis and J. tristani) are distributed in a narrow latitudinal band $\left(\sim 25^{\circ}\right.$ to $47^{\circ}$; Fig. 1$)$ in the Southern Hemisphere (Booth 2006) up to $200 \mathrm{~m}$ (Holthuis 1991) and possibly up to $600 \mathrm{~m}$ depth (Duhamel personal communication). These animals have a long pelagic larval duration (PLD; up to two years for J. edwardsii), with the potential for extensive dispersal (Bradford et al. 2015). Despite such a long PLD, all species have a restricted latitudinal distribution; for example, J. caveorum is only known from a single seamount in the eastern South Pacific Ocean (Webber \& Booth 1995). Phylogenetic relationships between Jasus species have been investigated with a limited number of mtDNA markers (Brasher et al. 1992; Ovenden et al. 1997). Ovenden et al. (1997) identified a clade containing J. edwardsii, J. Ialandii and J. frontalis, however, the relative branching order was not resolved by analysis of sequence variation in the cytochrome c oxidase subunit I (COI) and the $16 \mathrm{~S}$ ribosomal RNA sequences. In addition, the species J. tristani and J. paulensis, which occur in islands

99 and seamounts off the southern Atlantic and Indian Oceans, respectively, were hypothesized to have come 100 into secondary contact during past glacial periods, resulting in low levels of mtDNA differentiation (Ovenden 101 et al. 1997; Groeneveld et al. 2012). At the species level, population genetic studies have demonstrated a 102 general pattern of low, yet often significant, differentiation (Ovenden et al. 1992; Matthee et al. 2007; Porobić 103 et al. 2013; Thomas \& Bell 2013; Villacorta-Rath et al. 2016). Post-settlement selection and chaotic genetic patchiness, also described as a shifting, ephemeral genetic pattern, has also been observed in J. edwardsii, 
105 highlighting the uncertainties in predicting connectivity between populations of highly dispersive marine organisms (Villacorta-Rath et al. 2018).

Although a few studies suggest a recent divergence between Jasus lineages (Pollock 1990; Ovenden et al. 1997), relatively little attention has focused on investigating diversification processes in Jasus lobsters.

109 Here we investigate speciation processes in all the extant lobster species of the genus Jasus. This study aims 110 to test for evidence of admixture/introgression between species, investigating the genetic patterns associated 111 with habitat structure (continental shelf or seamount/island) and inferring the demographic history of Jasus 112 spp. using genome-wide single nucleotide polymorphisms (SNP).

Tissue samples of Jasus spp. were collected between 1995 and 2017 from 17 locations throughout the entire genus' range (Fig. 1). A total of 375 samples were collected (11 Jasus caveorum, $53 \mathrm{~J}$. frontalis, $41 \mathrm{~J}$. tristani, $129 \mathrm{~J}$. Ialandii, $49 \mathrm{~J}$. paulensis and $92 \mathrm{~J}$. edwardsii). Tissue was stored in $70 \%$ ethanol before processing. Total genomic DNA of J. caveorum museum samples was extracted using the QIAamp DNA Micro Kit (Qiagen) according to the manufacturer's instruction. The remaining tissue samples were extracted using NucleoMag ${ }^{\circledR}$ Tissue (Macherey-Nagel) following to the manufacturer's instructions.

Library preparation and sequencing was conducted by Diversity Arrays Technology, Canberra, Australia and followed standard protocols of DArTseq ${ }^{T M}$ genotyping technology (Kilian et al. 2012). Briefly, approximately $100 \mathrm{ng}(2 \mu \mathrm{L})$ of each sample was digested with the restriction enzymes PtsI and Sphl, and unique barcode sequences simultaneously ligated onto the ends of each resulting fragment as per Kilian et al. 2012. The Pstl-compatible adapter included an Illumina flow-cell attachment sequence, a primer sequence and unique barcode, with the reverse Sphl-compatible adaptor contained in the flow-cell attachment region. A minimum of $15 \%$ random technical replicates were included for downstream quality control. Each sample with fragments containing both Pstl and Sphl cut sites was amplified in PCR reactions using the following conditions: $94^{\circ} \mathrm{C}$ for $1 \mathrm{~min}$ then 30 cycles of $94^{\circ} \mathrm{C}$ for $20 \mathrm{~s}, 58^{\circ} \mathrm{C}$ for $30 \mathrm{~s}, 72{ }^{\circ} \mathrm{C}$ for $45 \mathrm{~s}$, and $72{ }^{\circ} \mathrm{C}$ for $7 \mathrm{~min}$. Samples were checked visually on an agarose gel to ensure complete digestion and uniform range of fragment sizes. Using approximately $10 \mu \mathrm{L}$ of each sample, samples were sequenced on a single flow-cell lane on the 
Libraries were demultiplexed and reads were filtered for overall quality $(-c,-q$ and $-r$ options) using

142 process_radtags in STACKS v.2.0b9 (Catchen et al. 2013). The Stacks pipeline denovo_map.p/ was executed to

143 run each of the Stacks modules individually (ustacks, cstacks, sstacks and populations). The formation of loci

144 was allowed with a maximum of two nucleotides between stacks $(M=2)$ and a minimum stack depth of three

145 ( $m=3$ ) among reads for accurate calling (ustacks module). Reads were aligned de novo with each other, and

146 a catalogue of putative RAD tags was created (cstacks module). Putative loci were searched against the catalog

147 (sstacks module) and further filtering was then conducted in the populations module.

$148 \quad$ Retained reads were present in at least $70 \%$ of samples within each species, were detected in all 149 species, had a rare allele frequency of at least $2 \%$ and had no more than 2 alleles detected. Potential paralogs 150 were excluded by removing markers with heterozygosity $>0.50$ within samples and analyses were restricted 151 to one random SNP per locus (using --write_random_snp). These filtering steps aimed to exclude as many SNPs 152 as was possible with genotyping errors and missing data.

\section{Genetic diversity and population structure}

Allelic richness, pairwise $\mathrm{F}_{S \mathrm{ST}}$ values and respective $\mathrm{p}$-values were estimated using hierfstat package in

R (Goudet 2005). The R package adegenet was used to estimate observed and expected heterozygosity, inbreeding coefficients and for discriminant analyses of principal components (DAPC) and membership probability plots (Jombart 2008). Outlier analyses were conducted in BayeScan to look for signatures of selection. Prior odds were set to 100 to minimize chances of false positives with 5,000 pilot runs, followed by

\section{Environmental data collection and analyses}

Initially, 13 environmental variables were obtained from Bio-Oracle (Assis et al. 2018; Table S1). Only uncorrelated variables $(r<0.6)$ were retained resulting in seven layers (surface and benthic temperature mean, surface salinity, surface and benthic current velocity, benthic iron and surface phytoplankton). Multiple regression of distance matrices (MRDM; Legendre et al., 2014) was used to examine the association of geographic distance (estimated as the shortest path distance in the ocean) with patterns of genetic differentiation (measured as pairwise $F_{S T}$ values), using the R package ecodist (Goslee \& Urban 2007). 
using the R package vegan (Oksanen et al. 2019). Significance was assessed using a permutation test (999 permutations) for redundancy analysis using the function anova.cca().

\section{Relationships among lineages}

The program TREEMIX v1.12 (Pickrell \& Pritchard 2012) was used to further investigate historical relationships among lineages. A maximum-likelihood (ML) phylogeny was first inferred and then single migration events between branches were sequentially added to determine whether migration/admixture events improve the likelihood fit. To formally test for admixture between Jasus spp., the three-population test (Reich et al. 2009) included with TREEMIX was used. In this test, the $f_{3}(\mathrm{X} ; \mathrm{A}, \mathrm{B})$ statistic is negative when a population $X$ does not form a simple tree with populations $A$ and $B$, but rather may be a mixture of $A$ and $B$.

\section{Demographic modelling}

Previous analysis suggests evidence of admixture between species pairs, and so we tested several hypothesis of divergence modes, aiming to identify speciation events through time, for each closely related pair of species: J. caveorum - J. frontalis, J. edwardsii - J. lalandii and J. tristani - J. paulensis. The species pairs were selected based on their genetic and morphological relationships (Holthuis \& Sivertsen 1967; George \& Kensler 1970; Brasher et al. 1992; Ovenden et al. 1997; Groeneveld et al. 2012; this study). For each pair, six models were built representing alternative modes of divergence considering possible scenarios: (SI) Strict Isolation, where the environment (e.g. sea level change and ocean currents) promoted allopatry; (IM) Isolation-with-Migration, with continuous gene flow through the speciation process; (AM) Ancient Migration, with an ancient gene flow event but recent isolation; (SC) Secondary Contact, with a recent gene flow event after past isolation; (PAM) Ancient Migration with two periods of gene flow, with two ancient gene flow events but recent isolation; and (PSC) Secondary Contact with two periods of contact, two recent gene flow events after past isolation. Six additional models were built to include expansion/contraction events in the initial models (suffix 'ex'). All models were implemented allowing for asymmetric migration rates (m12, m21).

Demographic inference was performed using the diffusion approximation method implemented in the software dadi (Gutenkunst et al. 2009). The function vcf2dadi in the R package radiator (Gosselin 2017) was used to create dadi SNP input files. We used the folded joint site frequency spectrum (JSFS) for model selection because the closest out-group (Sagmariasus verreauxi) was too distant (diverged around 11 Mya; Ovenden et al. 1997), which resulted in a highly reduced number of orientable polymorphisms. 
In total, 12 models were tested per species pair, fitted with the observed joint site frequency spectrum

(SFS) using 20 replicate runs per model and the best model was retained (Fig. S4). The Akaike information

criterion (AIC) was used to perform comparisons among models (Sakamoto et al. 1986).

To compare among nested models of increasing complexity and address over-parametrization issues

we used the comparative framework of Tine et al. (2014) by penalizing models which contain more

211 Score $=\frac{\left(\Delta_{\max }-\Delta \mathrm{AIC}_{\mathrm{i}}\right)}{\Delta_{\max }}$

213 where, $\Delta_{\max }$ corresponds to the difference in AIC between the worst and the best performing model $\left(\Delta_{\max }=\right.$

$\left.214 A I C_{\max }-A I C_{\min }\right)$ and $\triangle A I C_{i}=A I C_{i}-A I C_{\text {min. }}$. Therefore, the worst model has a score of 0 and the best model has a

215 score of 1 . To evaluate the relative probabilities of the different models within each species pair, Akaike 216 weights ( $\mathrm{W}_{\text {AIC }}$ ) were also calculated following:

where $R$ corresponds to the total number of models considered $(R=12)$. information about mutation rate per generation in Jasus spp. The ancestral effective population size $\left(\mathrm{N}_{\text {ref }}\right)$ before split for each species pair was estimated following:

with $\theta$ being the optimal multiplicative scaling factor, $\mu$ the mutation rate (fixed at $8 \times 10^{-8}$ mutations per site per generation; Obbard et al. 2012) and L the effective length of the genome explored:

where $\mathrm{x}$ is the number of SNPs originally detected from y RAD-tags of 73 bp present in the initial data set, and

$233 \mathrm{z}$ the number of SNPs retained, following Rougeux et al. (2017). Estimated units in $2 \mathrm{~N}_{\text {ref }}$ were converted to 234 years assuming a generation time of 10 years (Pecl et al. 2009). Estimated migration rates were divided by 


\section{Results}

\section{Genetic diversity and population structure}

Sequencing yielded a total of 1,501,921,855 quality-trimmed sequencing reads, providing an average

240 depth of coverage per individual over all SNPs of 58.9x. After applying the different filtering steps, 2,596 SNPs

common to all species were retained for subsequent analyses. The lowest values of observed heterozygosity,

242 expected heterozygosity, and allelic richness were observed for J. caveorum. While J. frontalis had the highest

243 inbreeding coefficients (0.502), all species had very similar values. The highest values of allelic richness were

244 observed for J. Ialandii (Table 1). The highest pairwise $\mathrm{F}_{\mathrm{ST}}$ values were observed for J. tristani - J. caveorum

245 and $J$. paulensis $-J$. caveorum $\left(F_{S T}=0.463\right.$ and $F_{S T}=0.436$, respectively, $\left.p<0.05\right)$, while the lowest values were 246 observed for J. tristani $-J$. paulensis $\left(\mathrm{F}_{\mathrm{ST}}=0.022, \mathrm{p}<0.01\right.$; Table 2$)$.

248 Table 1 Summary statistics of genetic diversity per species using 2,596 SNPs. $H_{0}$ : observed heterozygosity, $H_{E}$ :

249 expected heterozygosity, $F_{I S}$ : inbreeding coefficient, $A_{R}$ : allelic richness

\begin{tabular}{llllll}
\hline Species & Sample size & $\mathrm{H}_{\mathrm{O}}$ & $\mathrm{H}_{\mathrm{E}}$ & $\mathrm{F}_{\mathrm{IS}}$ & $\mathrm{A}_{\mathrm{R}}$ \\
\hline J. caveorum & 11 & 0.012 & 0.012 & 0.499 & 1.04 \\
J. frontalis & 53 & 0.064 & 0.065 & 0.502 & 1.32 \\
J. tristani & 41 & 0.092 & 0.104 & 0.500 & 1.31 \\
J. lalandii & 129 & 0.086 & 0.104 & 0.499 & 1.60 \\
J. paulensis & 49 & 0.087 & 0.103 & 0.498 & 1.31 \\
J. edwardsii & 92 & 0.084 & 0.100 & 0.501 & 1.34 \\
\hline & 375 & & & &
\end{tabular}

252 Table 2 Pairwise $F_{S T}$ values (below diagonal) and corresponding p-values (above diagonal) estimated using 253 hierfstat package in $\mathrm{R}$.

\begin{tabular}{lllllll}
\hline & J. caveorum & J. frontalis & J. tristani & J. lalandii & J. paulensis & J. edwardsii \\
\hline J. caveorum & 0 & 0.010 & 0.013 & 0.010 & 0.011 & 0.012 \\
J. frontalis & 0.081 & 0 & 0.007 & 0.005 & 0.006 & 0.007 \\
J. tristani & 0.463 & 0.206 & 0 & 0.007 & 0.008 & 0.009 \\
J. Ialandii & 0.305 & 0.137 & 0.387 & 0 & 0.006 & 0.007 \\
J. paulensis & 0.436 & 0.229 & 0.022 & 0.408 & 0 & 0.007 \\
J. edwardsii & 0.413 & 0.106 & 0.441 & 0.230 & 0.452 & 0 \\
\hline
\end{tabular}


bioRxiv preprint doi: https://doi.org/10.1101/2019.12.13.874883; this version posted December 15, 2019. The copyright holder for this preprint (which was not certified by peer review) is the author/funder, who has granted bioRxiv a license to display the preprint in perpetuity. It is made available under aCC-BY-NC-ND 4.0 International license.

No signatures of selection were detected by the outlier detection analyses (Fig. S1). Lobster species were grouped into three main clusters by discriminant analyses of principal components when using 2 PCs

258 (52.3\% variation) (Fig. 2). There was evidence of admixture, in particular between J. paulensis - J. tristani in 259 the membership probability plot and the DAPC results, and pairwise $F_{S T}$ values (Fig. 1 and 2). The first DAPC 260 axis (LD1) explained $29.9 \%$ of the variation and highlighted the divergence between habitat structure (i.e. J. 261 edwardsii and J. lalandii vs. remaining species; Fig. S2a), while the second DAPC axis (LD2), which explained $26222.4 \%$ of the variation, showed three main clusters and highlighted the differences between J. paulensis and 263 J. tristani and the remaining species (Fig. S2b).

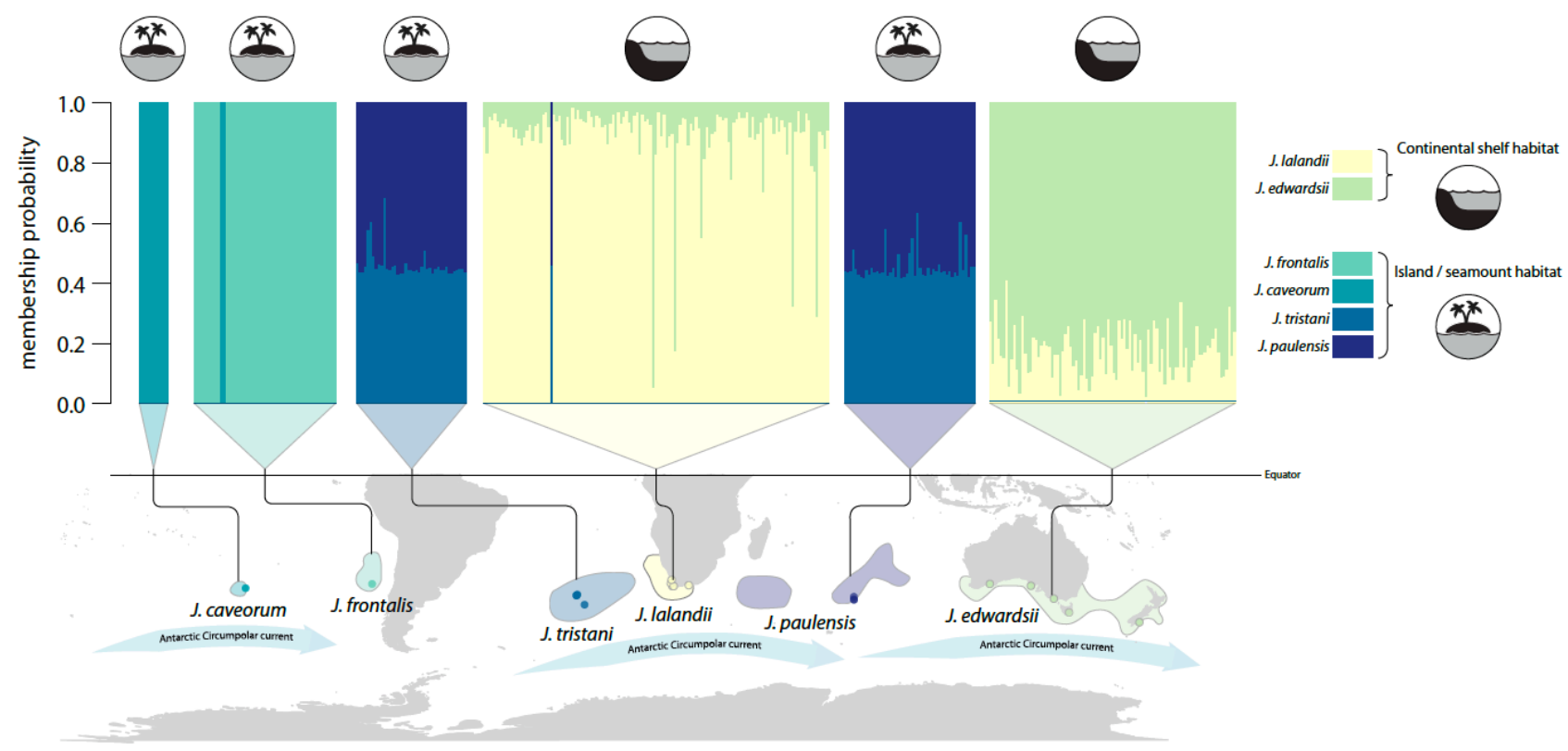

266 Fig. 1. Sample locations, approximate distribution range of Jasus spp. (adapted from Booth, 2006) and membership probability plot using 2 principal components.

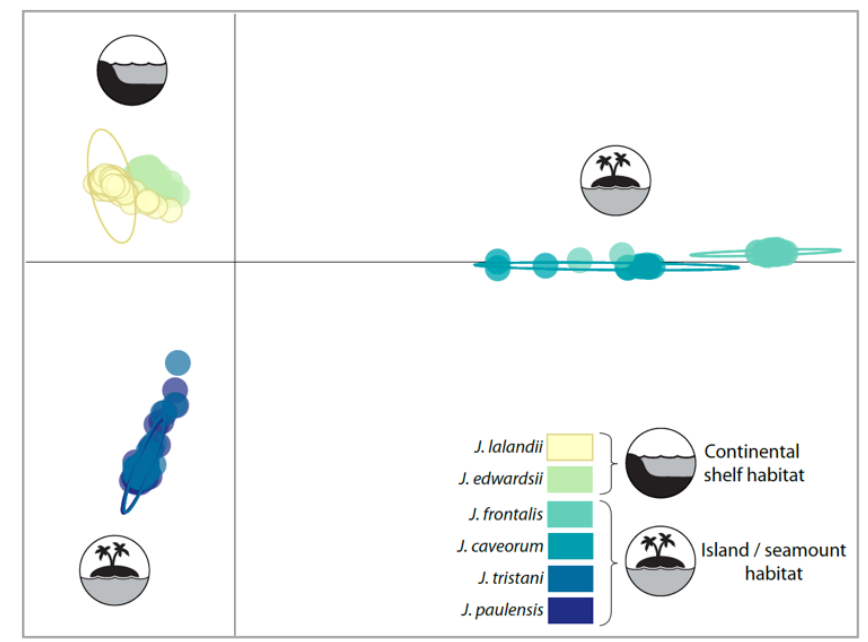

269 Fig. 2. Discriminant analyses of principal components (DAPC) of Jasus spp. using 2 principal components 270 (explaining $52.3 \%$ variation). 
bioRxiv preprint doi: https://doi.org/10.1101/2019.12.13.874883; this version posted December 15, 2019. The copyright holder for this preprint (which was not certified by peer review) is the author/funder, who has granted bioRxiv a license to display the preprint in perpetuity. It is made available under aCC-BY-NC-ND 4.0 International license.

Geographic distance explained $23.3 \%$ of the total genetic variation $\left(\mathrm{F}_{\mathrm{ST}}\right)$ between rock lobster species

274 ( $p<0.01)$, using multiple regression of distance matrices (MRDM). The model with all seven environmental

275 variables explained $52.9 \%$ of the total genetic variation between lobster species $(p<0.001)$, while the model

276 with the four most important environmental variables explained $51.4 \%$ of the total genetic variation

277 ( $p<0.001)$. Benthic mean temperature was the single environmental variable that explained most of the

278 genetic differentiation while controlling for the effects of geographic distance (41.3\%; $p<0.001$; Table 3 ).

All seven environmental variables explained $18 \%$ of the variation in rock lobster species $(p<0.001)$

280 when using the constrained ordination in RDA analyses. All values of the variance inflation factors were below 281 five, indicating that multicollinearity among the predictor variables is not inflating the model. The first five 282 constrained axes were significant in explaining the genetic variation between species (each explaining 53.3\%, $28325.3 \%, 12 \%, 5.2 \%$ and 2.2\%, respectively; $p<0.001$; Fig. 3). Genetic variation of J. caveorum and J. frontalis was 284 associated with higher surface temperature, while J. paulensis and J. tristani were associated with lower 285 surface temperature. J. edwardsii and J. lalandii were associated with higher benthic temperature, benthic 286 current velocity and benthic iron. Finally, J. lalandii was associated with higher surface phytoplankton, while 287 J. edwardsii was associated with higher surface current velocity (Fig. 3).

289 Table 3 Summary of the models for the multiple regression of distance matrices (MRDM) analyses using $\mathrm{F}_{\mathrm{ST}}$ as 290 a measure of genetic differentiation. GeoDist: geographic distance $(\mathrm{km})$; SurfTemp and BenTemp: Surface and 291 benthic temperature $\left({ }^{\circ} \mathrm{C}\right)$; SurfSal: Surface salinity (PSS); SurfCurren and BenCurren: Surface and benthic 292 current velocity $\left(\mathrm{m}^{\mathrm{s}} \mathrm{s}^{-1}\right)$; Benlron: Benthic dissolved iron $\left(\mathrm{mmol} . \mathrm{m}^{-3}\right)$; SurfPhyto: surface phytoplankton 293 (mmol.m $\mathrm{m}^{-3}$.

\begin{tabular}{llc}
\hline Factors & $\mathbf{r}^{\mathbf{2}}$ & $\mathbf{p}$-value \\
\hline GeoDist & 0.233 & $<0.01$ \\
GeoDist + SurfTemp & 0.235 & $<0.001$ \\
GeoDist + BenTemp & 0.413 & $<0.001$ \\
GeoDist + SurfSal & 0.233 & $<0.001$ \\
GeoDist + SurfCurren & 0.238 & $<0.01$ \\
GeoDist + BenCurren & 0.298 & $<0.001$ \\
GeoDist + Benlron & 0.237 & $<0.001$ \\
GeoDist + SurfPhyto & 0.290 & $<0.001$ \\
GeoDist + SurfTemp + BenTemp + SurfSal + SurfCurren + BenCurren + BenIron + & 0.529 & $<0.001$ \\
SurfPhyto & 0.514 & $<0.001$ \\
GeoDist + SurfTemp + BenTemp + BenCurren + SurfPhyto & &
\end{tabular}




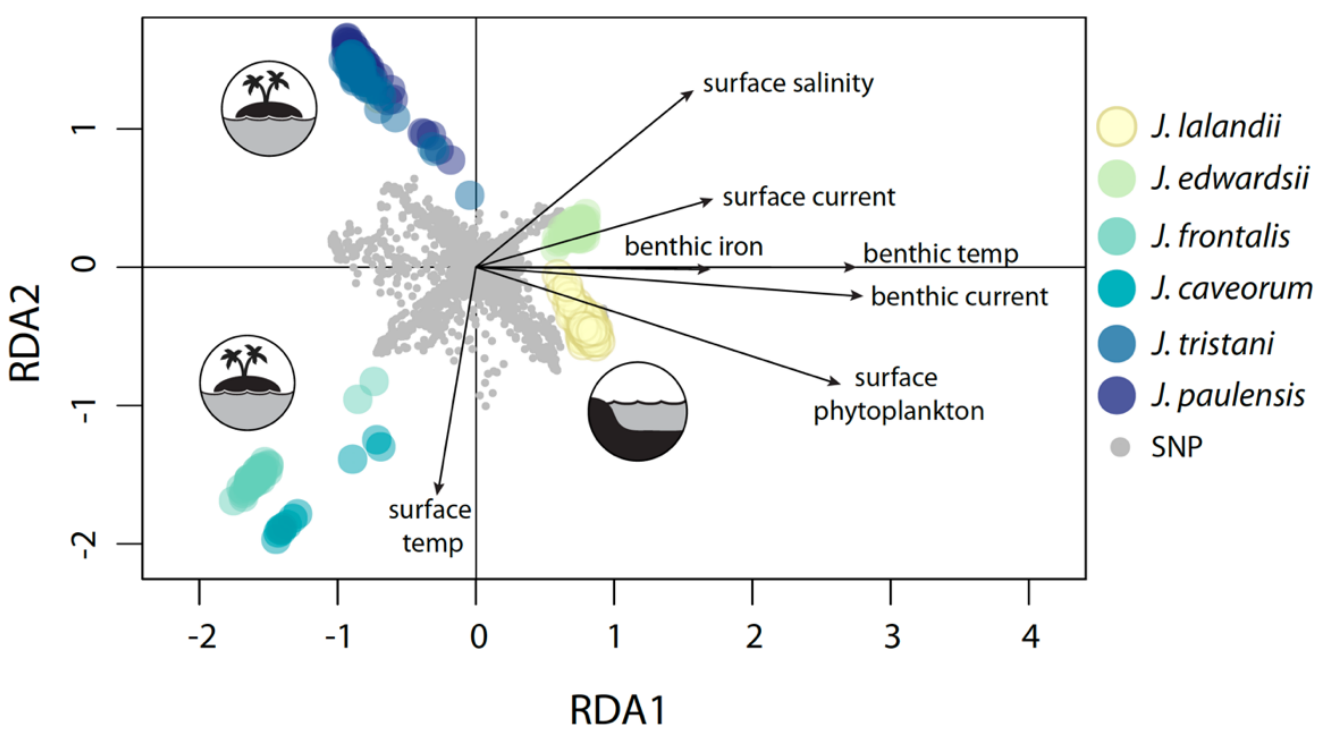

299 (see Table 3 for a detailed description).

\section{Relationships among lineages}

Results from TREEMIX identified three ancestral events of admixture (Fig. S3). However, from the three-population test of admixture, only two $f_{3}$ values were negative with associated Z-scores $<-0.6$, indicating evidence that $J$. tristani does not form a simple tree with J. paulensis, J. Ialandii and J. edwardsii, but rather may be a mixture of these (Table S2, Supporting information). Therefore, the three-population test supported the ancestral event of admixture detected by TREEMIX from the most recent common ancestor (MRCA) of $J$. lalandii and J. edwardsii to J. tristani. The genetic relationships among species inferred by TREEMIX revealed similar patterns to the genetic differentiation analyses, clearly separating species pairs J. lalandii-J. edwardsii,

\section{Demographic modelling}

In general, SC and PSC models provided better fits to the data with good predictions of the joint site 318 AM, PAM and SI had better support for the J. caveorum - J. frontalis pair (Table S3, Fig. S4). Incorporating 319 population expansion events (suffix 'ex') improved the fit of PSC models for all species pairs but there was not 320 a clear pattern for PAM models. In contrast, the strict isolation (SI) and ancient migration (AM, PAM) models 321 were weakly supported for the J. paulensis - J. tristani and J. edwardsii - J. lalandii pairs while the secondary contact models (SC, PSC) were weakly supported for the J. caveorum - J. frontalis pair (Table S3, Fig. S4). 
Asymmetries in gene flow with ratios of $\mathrm{m}_{21} / \mathrm{m}_{12}$ indicated a stronger migration from population two

324 to population one in all species pairs, and the lower proportion of migrants was observed for the J. edwardsii

325 - J. Ialandii pair (Fig. 4, Table 4). Detailed results for demographic inferences are provided in Table S3, Fig. 4,

326 Table 4, Fig. S4 and Fig. S5 (supporting information).

327 The best supported model for the J. paulensis - J. tristani pair was PSCex (Table S3). Within this model, 328 total divergence time between species was approximately $25,826 \pm 6,286$ years ago (Table 4). The period 329 without contact was approximately 5.4 times longer than the period with secondary contact. The best 330 supported model for the J. edwardsii - J. lalandii pair was PSCex (Table S3). Total divergence time between J. 331 edwardsii and J. Ialandii was approximately 38,460 $\pm 12,242$ years ago (Table 4). The period without contact 332 was approximately 38.8 times longer than the period with secondary contact. Finally, the best supported 333 model for the J. caveorum - J. frontalis pair was PAMex (Table S3). Within this model, total divergence time 334 between species was approximately 28,709 $\pm 12,674$ years (Table 4 ) and the period without contact was 335 approximately 8.1 times longer than the period with ancient migration. Therefore, divergence times with 336 errors overlap across the three species pairs and was estimated to be between 19,540 and 32,112 years for $J$. 337 paulensis - J. tristani, 26,218 and 50,702 years for J. edwardsii - J. lalandii and 16,035 and 41,383 years for J. 338 caveorum - J. frontalis. 

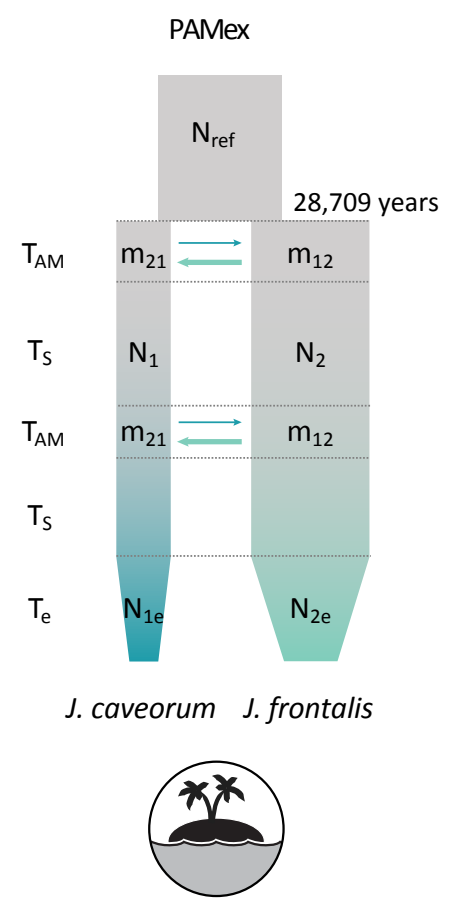

PSCex
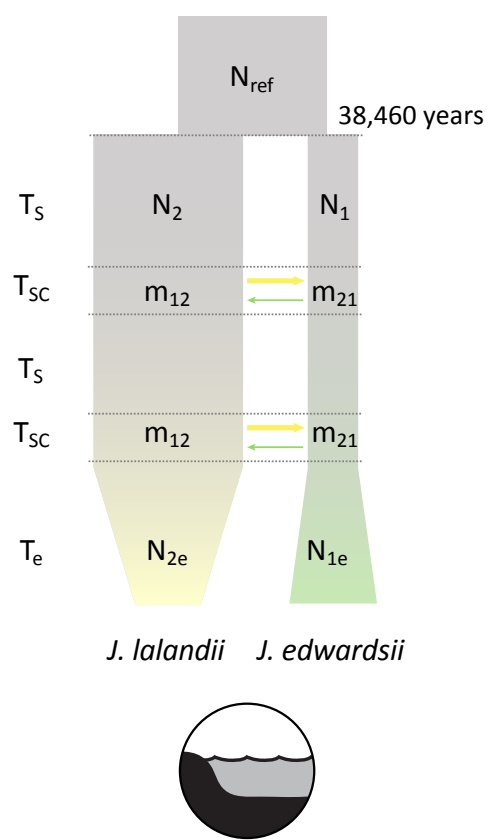

PSCex
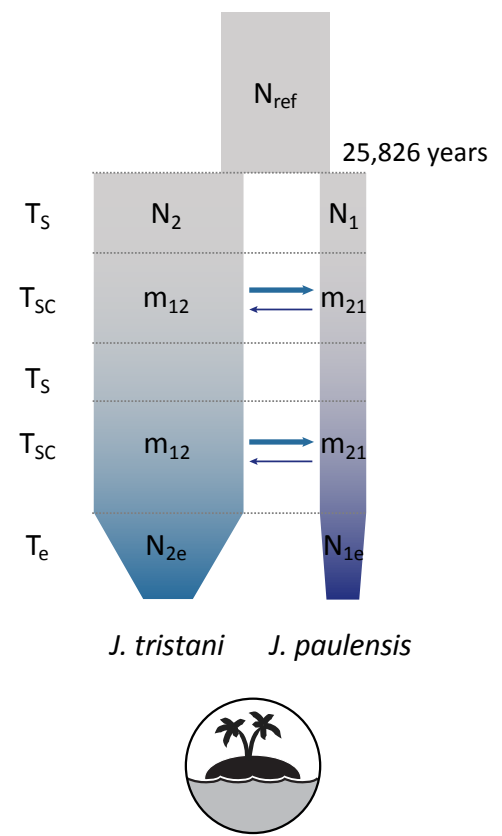

342 Fig. 4. Representation of the best demographic model for each species pair; J. caveorum - J. frontalis: ancient 343 migration with two periods of ancient gene flow and recent population contraction (PAMex); J. lalandii - J.

344 edwardsii and J. tristani - J. paulensis: secondary contact with two periods of contact and recent population 345 expansion (PSCex). Asymmetric migration rates $\left(m_{21}\right.$ and $\left.m_{12}\right)$ are represented by the arrows with higher rates 346 of migration from population two to population one for all species pairs (thicker lines in arrows). Width of the boxes represent sizes of the ancestral population $\left(\mathrm{N}_{\text {ref }}\right)$, population sizes before expansion/contraction $\left(\mathrm{N}_{1}, \mathrm{~N}_{2}\right)$

348 and population sizes after expansion/contraction $\left(\mathrm{N}_{1 \mathrm{e}}, \mathrm{N}_{2 \mathrm{e}}\right)$. $\mathrm{T}_{\mathrm{s}}$ is the time of divergence in strict isolation, $\mathrm{T}_{\mathrm{sc} / \mathrm{Am}}$ the time of secondary contact or ancient migration and $T_{\mathrm{e}}$ the time of expansion. 
352 Table 4. Parameters estimates for the best model of each species pair with standard deviation. J. paulensis 353 J. tristani: secondary contact with two periods of contact and recent population expansion (PSCex); J. edwardsii 354 - J. lalandii: secondary contact and recent population expansion (SCex); J. caveorum - J. frontalis: ancient 355 migration with two periods of ancient gene flow and recent population contraction (PAMex).

\begin{tabular}{llll}
\hline Species group & $\begin{array}{l}\text { 1: J. paulensis, } \\
\text { 2: J. tristani }\end{array}$ & $\begin{array}{l}\text { 1: J. edwardsii, } \\
\text { 2: J. lalandii }\end{array}$ & $\begin{array}{l}\text { 1: J. caveorum, } \\
\text { 2: J. frontalis }\end{array}$ \\
\hline Best Model & PSCex & PSCex & PAMex \\
$\mathbf{K}$ & 9 & 9 & 9 \\
$\mathbf{N}_{\text {ref }}$ & 43.96 & 85.64 & 64.19 \\
$\mathbf{N}_{\mathbf{1}}$ & $3.50 \pm 0.84$ & $1.50 \pm 0.25$ & $1.30 \pm 0.35$ \\
$\mathbf{N}_{\mathbf{2}}$ & $49.67 \pm 19.38$ & $41.01 \pm 15.61$ & $19.19 \pm 9.09$ \\
$\mathbf{N}_{1 \mathbf{e}}$ & $0.67 \pm 0.16$ & $2.44 \pm 0.41$ & $0.05 \pm 0.24$ \\
$\mathbf{N}_{\mathbf{2 e}}$ & $2.52 \pm 0.53$ & $1.28 \pm 0.34$ & $0.20 \pm 0.23$ \\
$\mathbf{m}_{12}$ & $11.00 \pm 3.77$ & $1.77 \pm 0.23$ & $7.71 \pm 2.33$ \\
$\mathbf{m}_{\mathbf{2 1}}$ & $2.59 \pm 2.22$ & $0.09 \pm 0.16$ & $1.99 \pm 0.36$ \\
$\mathbf{T}_{\mathrm{s}}$ & $11.94 \pm 2.67$ & $10.66 \pm 3.37$ & $9.74 \pm 4.48$ \\
$\mathbf{T}_{\text {sc/AM }}$ & $2.20 \pm 0.70$ & $0.27 \pm 0.10$ & $1.20 \pm 0.19$ \\
$\mathbf{T}_{\mathbf{e}}$ & $0.51 \pm 0.20$ & $0.29 \pm 0.11$ & $0.24 \pm 0.27$ \\
$\mathbf{T}_{\text {total }}$ & $29.29 \pm 7.15$ & $22.46 \pm 7.15$ & $22.36 \pm 9.87$ \\
${ }^{*} \mathbf{m}_{12}$ & $0.12 \pm 0.04$ & $0.01 \pm 0.001$ & $0.06 \pm 0.02$ \\
${ }^{*} \mathbf{m}_{21}$ & $0.03 \pm 0.03$ & $0.00 \pm 0.00$ & $0.01 \pm 0.00$ \\
${ }^{*} \mathbf{T}_{s}$ & $10,524 \pm 2,346$ & $18,258 \pm 5,769$ & $12,507 \pm 5,746$ \\
${ }^{*} \mathbf{T}_{\text {sc/AM }}$ & $1,941 \pm 618$ & $470 \pm 167$ & $1,541 \pm 239$ \\
${ }^{*} \mathbf{T}_{\mathbf{e}}$ & $447 \pm 179$ & $503 \pm 185$ & $306 \pm 352$ \\
${ }^{*} \mathbf{T}_{\text {total }}$ & $25,826 \pm 6,286$ & $38,460 \pm 12,242$ & $28,709 \pm 12,674$ \\
\hline${ }^{K}: T_{\text {Th }}$ & & &
\end{tabular}

$\mathrm{K}:$ The number of free parameters in the model

$\mathrm{N}_{\text {ref: }}$ The effective size of the ancestral population before the split

$\mathrm{N}_{1}$ : The effective size of population 1 before expansion

$\mathrm{N}_{2}$ : The effective size of population 2 before expansion

$\mathrm{N}_{1 \mathrm{e}}$ : The effective size of population 1 after expansion

$\mathrm{N}_{2 \mathrm{e}}$ : The effective size of population 2 after expansion

$\mathrm{m}_{12}$ : The neutral movement of genes from population 2 to population 1 in units of $2 \mathrm{~N}_{\text {ref }}$ generations

$\mathrm{m}_{21}$ : The neutral movement of genes from population 1 to population 2 in units of $2 \mathrm{~N}_{\text {ref }}$ generations

$\mathrm{T}_{\mathrm{s}}$ : The time of divergence in strict isolation in units of $2 \mathrm{~N}_{\text {ref }}$ generations

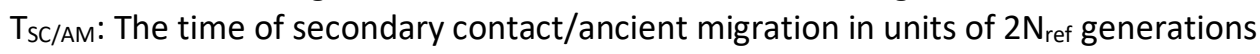

$\mathrm{T}_{\mathrm{e}}$ : The time of expansion in units of $2 \mathrm{~N}_{\text {ref }}$ generations

$T_{\text {total: }}$ : The total time since the split in units of $2 \mathrm{~N}_{\text {ref }}$ generations

${ }^{*} m_{12}$ : The proportion of migrants per generation from population 2 to population 1

${ }^{*} m_{21}$ : The proportion of migrants per generation from population 1 to population 1

${ }^{*} T_{s}$ : The time of divergence in strict isolation in units of numbers of years

* Tsc/Am: The time of secondary contact/ancient migration in units of numbers of years

${ }^{*} \mathrm{~T}_{\mathrm{e}}$ : The time of expansion in units of numbers of years

${ }^{*} T_{\text {total }}:$ The total time since the split in units of numbers of years 


\section{Discussion}

Here we investigated genome-wide divergence and introgression patterns in all extant species of rock lobsters (Jasus spp.) for the first time. Genetic differentiation patterns revealed the effects of the environment and geographical isolation. Species that were associated with the same habitat structure (continental shelf or seamount/island) were more closely related to each other than with species from a different habitat structure. Benthic temperature was the single environmental variable that explained most of the genetic differentiation

$368\left(\mathrm{~F}_{\mathrm{ST}}\right)$ while controlling for the effects of geographic distance $(41.3 \%)$, and J. edwardsii and J. lalandii were 369 associated with higher mean benthic temperatures. We also detected multiple introgression events (gene 370 flow) since the first divergence in all species pairs.

Divergence during Pleistocene

Divergence times between species pairs estimated by demographic modelling overlap across all species comparisons and suggest that global/widespread processes might have driven initial divergence across all species. During the divergence period estimated for Jasus spp. (from 38,460 to 25,826 years ago) global temperature and sea levels were decreasing (Clark et al. 2009). Sea level was 65 to 125 metres lower than today possibly creating more shallow benthic habitat for lobsters in the open ocean in contrast with a reduction in the available continental shelf habitat (Schaaf 1996). A significant increase in the Southern Ocean barotropic stream function occurred between 49,000 and 28,500 years ago (Fogwill et al. 2015), which may have increased the dispersal potential of larvae. Also, a large increase in subantarctic productivity occurred 35-65,000 years ago during Heinrich events H4-H6 (Sachs \& Anderson 2005), which may have enabled planktotrophic larvae to survive for longer periods of time. These processes may have facilitated worldwide dispersal and colonization of circumpolar habitats by the Jasus spp. ancestor during this period (Fig. 5).

During the last glacial maximum (LGM) about 19,000-22,000 years ago, temperature and sea levels reached minimum values (Clark et al. 2009). New ecological zones could have appeared, favouring species 386 associated with seamount and island habitats, which could explain the ancient secondary contact events for 387 J. caveorum and J. frontalis (Schaaf 1996). On the other hand, there was a shrinkage of the shallow continental 388 margins habitat and species therein (Schaaf 1996; Holland 2012). Species associated with continental shelf 389 habitat could also have shifted northwards while tracking their thermal optima. These changes in habitat may have resulted in longer periods of isolation between the continental shelf associated species J. Ialandii and J. edwardsii. 


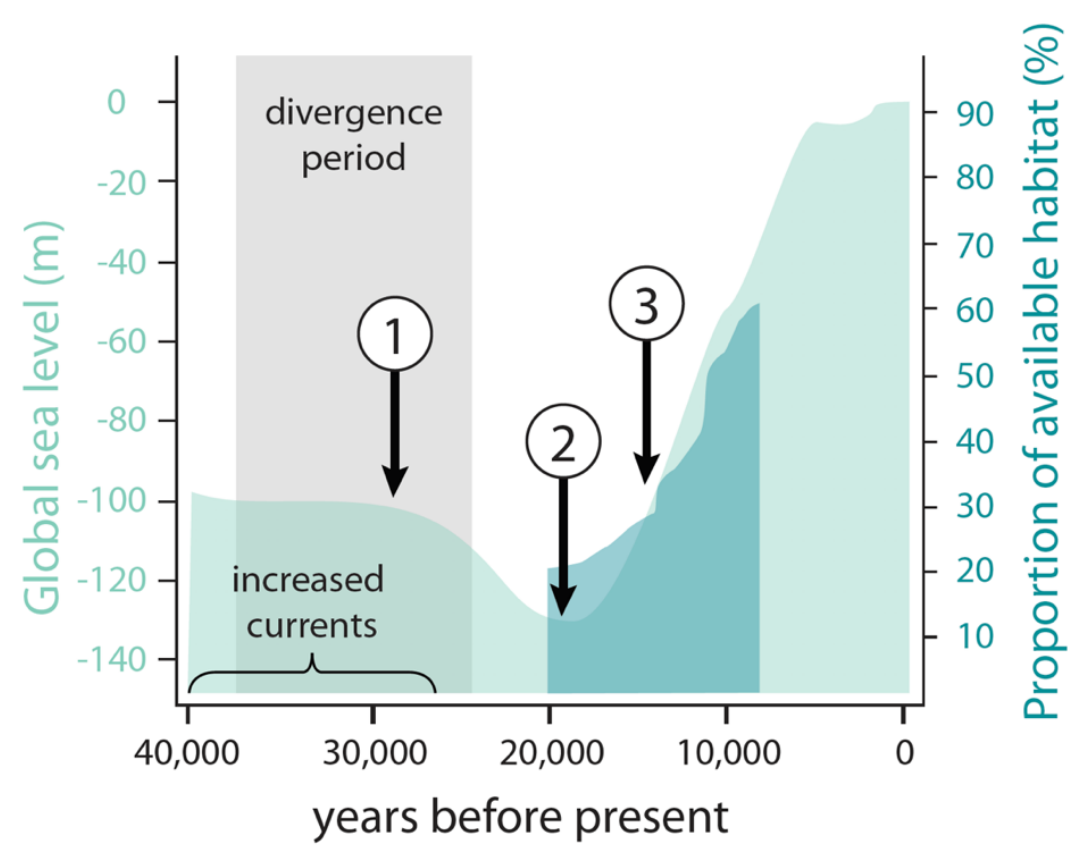

393 Fig. 5. Changes in global sea level (adapted from Huybrechts 2002) and proportion of available habitat in the 394 photic zone (Schaaf 1996) relative to present day. 1) Antarctic sea ice expands around 28,500 years ago 395 (Fogwill et al. 2015); 2) Ocean currents reduction (around 22,000 years ago; Alloway et al. 2007); 3) West Antarctic Ice Sheet deglaciation (around 14,500 years ago; Clark et al. 2009).

Transition from the LGM to the Holocene precipitated further changes in the available shallow benthic habitat for lobsters with the increase in sea levels and temperature (Clark et al. 2009). There were two major expansions of available shallow benthic habitat at 14,000 and 11,500 years (Schaaf 1996) which, for example, could have increased the suitable habitat for J. frontalis, having a positive effect on the population size and the effective population size (Porobić et al. 2013). However, the variation of the photic sea-bottom area was not linear nor directly correlated with the sea-level oscillations, but reflected topography patterns (Schaaf 1996). These fluctuations in available habitat resulted in alternating periods of isolation and gene flow that have shaped the present genetic signatures of Jasus lobsters (Fig. 5).

Are species genetically isolated?

The present study suggests that global processes might have driven initial divergence across all Jasus species. However, current genetic signatures highlight the complexities exclusive to each species evolution. For example, J. edwardsii and J. Ialandii were the most genetically differentiated species pair $\left(\mathrm{F}_{\mathrm{ST}}=0.230\right)$, followed by J. caveorum - J. frontalis $\left(\mathrm{F}_{S \mathrm{ST}}=0.081\right)$ and J. tristani - J. paulensis $\left(\mathrm{F}_{\mathrm{ST}}=0.022\right)$. This was in agreement

412 with the parameters estimated from demographic modelling, in particular the period of gene flow estimated 413 for each species pair (approximately $470 \pm 167$ years, 1,541 \pm 239 years and 1,941 \pm 618 years, respectively). 
Our study provides genome-wide evidence of admixture between J. paulensis - J. tristani that also

415 showed great genetic similarity. Although George \& Kensler (1970) have noted that J. tristani and J. paulensis

416 possess a significant difference in the abdominal sculpture index, genetic evidence suggests that these species

417 can be synonymized as J. paulensis, which was also proposed by Groeneveld et al. (2012) using the

418 mitochondrial cytochrome oxidase I gene. As a comparison, since initial divergence, J. tristani and J. paulensis

419 spent 4.1 times longer in secondary contact than J. edwardsii-J. lalandii and 1.2 times longer than J. caveorum

420 and J. frontalis. The Tristan da Cunha and Gough Islands (current distribution of J. tristani) and the Amsterdam

421 and St. Paul Islands (current distribution of J. paulensis) have been grouped in the same zoogeographic

422 province (called the West Wind Drift Islands Province) based on endemic fish fauna distribution (Collette \&

423 Parin 1991). Therefore, the distribution of marine species with a pelagic larvae stage may be influenced by the

424 currents of the West Wind Drift and the long periods of gene flow may explain the close relationship between

425 J. tristani and J. paulensis.

426 Species associated with continental shelf habitat J. edwardsii and J. lalandii were genetically more 427 closely related to each other than to J. tristani and J. paulensis (island/seamount habitat) despite their 428 geographic locations (i.e. J. lalandii is geographically closer to J. tristani and J. paulensis than to J. edwardsii; 429 Fig. 1). Although connectivity would be possible between these species groups given the dispersal potential 430 (indeed, J. lalandii larvae have been found in the southwest Indian Ocean as far east as Amsterdam Island, 431 adjacent to the J. paulensis habitat (Booth \& Ovenden 2000)), species appear to be adapted to local 432 environmental conditions. Our results show that benthic temperature might be a limiting factor affecting gene 433 flow between species from island/seamount and continental shelf habitat. Temperature is important for 434 regulating the rate of embryological development in lobsters (Phillips 2013) and could limit reproduction of species adapted to local benthic temperatures.

436 It has been shown that during the post-larval or puerulus stage, J. edwardsii are able to recognize 437 environmental cues such as chemical, acoustic and substrate cues and increase settlement success in suitable 438 habitats (Stanley et al. 2015; Hinojosa et al. 2016, 2018). Magnetism is also an important cue for adult Western 439 Rock Lobster, Panulirus cygnus (Lestang 2014) and adults and postlarvae of spiny lobster Panulirus argus (Boles 440 \& Lohmann 2003; Kough et al. 2014; Ernst \& Lohmann 2016). Our results show that genetic diversity of $J$. 441 Ialandii and J. edwardsii is associated with benthic iron. Therefore, it is possible that Jasus larvae are able to 442 use environmental cues such as magnetism for orientation and different species have adapted to recognize 443 local ecotypes and settle on habitats with contrasting structure. Ovenden et al. (1997) also suggested that the 444 common ancestor of J. tristani and J. paulensis may have been able to recognize environmental cues from 445 island and seamount habitats that allowed them to colonize mid-ocean habitats during glacial periods. 
In highly dispersive marine taxa, interglacial recolonization of high-latitude habitats can occur rapidly

448 (Hewitt 2000). Such patterns have been established for a range of Northern Hemisphere marine species (e.g.

449 Marko 2004; Ledoux et al. 2018), but relatively little is known about the genetic effects of recent glaciations

450 in the Southern Hemisphere (but see e.g. Fraser et al. 2009; Strugnell et al. 2012; Porobić et al. 2013). This

451 study revealed genome-wide patterns of divergence and introgression in all extant species of a highly

452 dispersive marine taxa for the first time. While results point to the important role of demographic and neutral

453 processes of differentiation between species pairs, it also suggests a possible effect of selection in promoting

454 genetic divergence between habitats. Future studies should address the role of adaptive processes to

455 elucidate their relative contribution in shaping genome divergence and speciation of Jasus lobsters and to

456 better understand how future environmental change will impact species distribution.

Data availability

459 Raw demultiplexed sequencing data will be available at Dryad. Pipelines for de novo assembly, genetic 460 structure, environmental association and demographic inference analyses will be available at github after 461 publication.

\section{Acknowledgments}

Funding for this research was provided by an Australian Research Council Discovery Project grant (Project No. DP150101491) awarded to J.M.S., J.J.B., B.S.G. and N.P.M. We would like to thank Gary Carlos (University of Tasmania), Colin Fry (University of Tasmania), Daniel lerodiaconou (Deakin University), Kent Way, Andrew Kent, Geoff Liggins, Marcus Miller, Giles Ballinger, Darrel Sykes (DAFF), Rick Webber (Te Papa Museum), Jason How (Department of Fisheries, Western Australia) and Sadie Mills (NIWA) for field assistance and sample collection; T.A.A.F. (Terres Australes et Antarctiques Françaises), for their French fisheries observer service "COPEC", the fishery observer Sophie Cascade on board the F.V. "AUSTRAL" and Charlotte Chazeau to have made available biological scientific samples and data of Jasus paulensis from catches in the SaintPaul/Amsterdam French EEZ; the help of crew has also been appreciated. C.E.H was supported by FONDECYT grants \#1170815.

\section{Author contributions}

All authors contributed insights about data analysis, interpretation of results and edited the final drafts of 


\section{References}

Alloway B V, Lowe DJ, Barrell DJA, Newnham RM, Almond PC, Al E (2007) Towards a climate event stratigraphy for New Zealand over the past 30000 years (NZ-INTIMATE project). Journal of Quaternary Science, 22, 9-35.

Arendt D, King N, Carroll SB, Wittopp P, Koonin E, Kruglyak L (2016) Big Questions in Evolution. Cell, 166, 528-529.

Assis J, Tyberghein L, Bosch S, Verbruggen H, Serrão EA, De Clerck O (2018) Bio-ORACLE v2.0: Extending marine data layers for bioclimatic modelling. Global Ecology and Biogeography, 27, 277-284.

Benardine Jeffrey I, Hale P, Degnan BM, Degnan SM (2007) Pleistocene isolation and recent gene flow in Haliotis asinina, an Indo-Pacific vetigastropod with limited dispersal capacity. Molecular Ecology, 16, 289-304.

Benestan L, Quinn BK, Maaroufi H, Laporte M, Clark FK, Greenwood SJ, Rochette R, Bernatchez L (2016) Seascape genomics provides evidence for thermal adaptation and current-mediated population structure in American lobster (Homarus americanus). Molecular Ecology, 25, 5073-5092.

Boles LC, Lohmann KJ (2003) True navigation and magnetic maps in spiny lobsters. Nature, 421, 60-63. Booth JD (2006) Jasus species. In 'Lobsters: Biology, Management, Aquaculture and Fisheries'. (Ed.B. F. Phillips.). Blackwell Scientific Publications: Oxford.

Booth JD, Ovenden JR (2000) Distribution of Jasus spp. (Decapoda: Palinuridae) phyllosomas in southern waters: Implications for larval recruitment. Marine Ecology Progress Series, 200, 241-255.

Bradford RW, Griffin D, Bruce BD (2015) Estimating the duration of the pelagic phyllosoma phase of the southern rock lobster, Jasus edwardsii (Hutton). Marine and Freshwater Research, 66, 213-219.

Brasher D, Ovenden J, White R (1992) Mitochondrial DNA variation and phylogenetic relationships of Jasus spp.(Decapoda: Palinuridae). Journal of Zoology, 227, 1-16.

Butlin RK, Galindo J, Grahame JW (2008) Sympatric, parapatric or allopatric: The most important way to classify speciation? Philosophical Transactions of the Royal Society B: Biological Sciences, 363, 29973007.

Clark PU, Dyke AS, Shakun JD, Carlson AE, Clark J, Wohlfarth B, Mitrovica JX, Hostetler SW, McCabe AM (2009) The Last Glacial Maximum. Science, 325, 710-714.

Collette BB, Parin N V (1991) Shallow-Water Fishes of Walters Shoals, Madagascar Ridge. Bulletin of Marine 
Science, 48, 1-22.

Crow KD, Munehara H, Bernardi G (2010) Sympatric speciation in a genus of marine reef fishes. Molecular Ecology, 19, 2089-2105.

Davis KE, Hill J, Astrop TI, Wills MA (2016) Global cooling as a driver of diversification in a major marine clade. Nature Communications, 7, 1-8.

Ernst DA, Lohmann KJ (2016) Effect of magnetic pulses on Caribbean spiny lobsters: Implications for magnetoreception. Journal of Experimental Biology, 219, 1827-1832.

Excoffier L, Dupanloup I, Huerta-Sánchez E, Sousa VC, Foll M (2013) Robust Demographic Inference from Genomic and SNP Data. PLoS Genetics, 9.

Feder JL, Egan SP, Nosil P (2012) The genomics of speciation-with- gene-flow. Trends in Genetics, 28, 342350.

Fogwill CJ, Turney CSM, Hutchinson DK, Taschetto AS, England MH (2015) Obliquity Control On Southern Hemisphere Climate During The Last Glacial. Scientific Reports, 5, 1-10.

Forester BR, Lasky JR, Wagner HH, Urban DL (2018) Comparing methods for detecting multilocus adaptation with multivariate genotype-environment associations. Molecular Ecology, 2215-2233.

Fraser Cl, Nikula R, Spencer HG, Waters JM (2009) Kelp genes reveal effects of subantarctic sea ice during the Last Glacial Maximum. Proceedings of the National Academy of Sciences of the United States of America, 106, 3249-3253.

George RW, Kensler CB (1970) Recognition of marine spiny lobsters of the Jasus lalandii group (crustacea:

Goslee SC, Urban DL (2007) The ecodist package for dissimilarity-based analysis of ecological data. Journal Of Statistical Software, 22, 1-19.

Gosselin T (2017) radiator: RADseq Data Exploration, Manipulation and Visualization using R. R package version 0.0.5.

Goudet J (2005) HIERFSTAT, a package for $r$ to compute and test hierarchical F-statistics. Molecular Ecology Notes, 5, 184-186.

Groeneveld JC, Von der Heyden S, Matthee CA (2012) High connectivity and lack of mtDNA differentiation among two previously recognized spiny lobster species in the southern Atlantic and Indian Oceans. Marine Biology Research, 8, 764-770.

Gutenkunst RN, Hernandez RD, Williamson SH, Bustamante CD (2009) Inferring the joint demographic history of multiple populations from multidimensional SNP frequency data. PLoS Genetics, 5.

Hewitt G (2000) The genetic legacy of the Quaternary ice ages. Nature, 405, 907-913.

Hinojosa I, Gardner C, Green B, Jeffs A (2018) Coastal chemical cues for settlement of the southern rock lobster, Jasus edwardsii. Bulletin of Marine Science, 1-16. 
Hinojosa IA, Green BS, Gardner C, Hesse J, Stanley JA, Jeffs AG (2016) Reef sound as an orientation cue for shoreward migration by pueruli of the rock lobster, Jasus edwardsii. PLOS ONE, 11, 1-15.

Holland SM (2012) Sea level change and the area of shallow-marine habitat: implications for marine biodiversity. Paleobiology, 38, 205-217.

Holthuis LB (1991) Marine lobsters of the world. An annotated and illustrated catalogue of species of interest to fisheries known to date. FAO Fisheries Synopsis. No. 125, Vol. 13. Rome, FAO.

Holthuis LB, Sivertsen E (1967) The Crustacea Decapoda, Mysidacea and Cirripedia of the Tristan da Cunha Archipelago, with a revision of the "frontalis" subgroup of the genus Jasus. Res. Norv. Scient. Exp. Tristan da Cunha 1937-1938, 52, 1-55.

Huybrechts P (2002) Sea-level changes at the LGM from ice-dynamic reconstructions of the Greenland and Antarctic ice sheets during the glacial cycles. Quaternary Science Reviews, 21, 203-231.

Jombart T (2008) Adegenet: A R package for the multivariate analysis of genetic markers. Bioinformatics, 24, 1403-1405.

Kough AS, Paris CB, Staaterman E (2014) In situ swimming and orientation behavior of spiny lobster (Panulirus argus) postlarvae. Marine Ecology Progress Series, 504, 207-219.

Ledoux JB, Frleta-Valić M, Kipson S, Antunes A, Cebrian E, Linares C, Sánchez P, Leblois R, Garrabou J (2018) Aschenbrenner-Kilian M, Evers M, Peng K, Cayla C, Hok P, Uszynski G (2012) Diversity Arrays
Technology: A Generic Genome Profiling Technology on Open Platforms. In: Data Production and Analysis in Population Genomics. Methods in Molecular Biology, vol 888. (eds Pompanon F, Bonin A), pp. 67-89. Humana Press, Totowa.

Postglacial range expansion shaped the spatial genetic structure in a marine habitat-forming species: Implications for conservation plans in the Eastern Adriatic Sea. Journal of Biogeography, 45, 26452657.

Legendre P, Lapointe F-J, Casgrain P (1994) Modeling Brain Evolution from Behavior: A Permutational Regression Approach. Evolution, 48, 1487-1499.

Lestang S (2014) The orientation and migratory dynamics of the western rock lobster, Panulirus cygnus, in Western Australia. ICES Journal of Marine Science, 71, 1052-1063.

Lowe WH, Allendorf FW (2010) What can genetics tell us about population connectivity? Molecular ecology, 19, 3038-51.

Manel S, Holderegger R (2013) Ten years of landscape genetics. Trends in Ecology and Evolution, 28, 614- 
621.

Marko PB (2004) “What's larvae got to do with it?" Disparate patterns of post-glacial population structure in two benthic marine gastropods with identical dispersal potential. Molecular Ecology, 13, 597-611.

Matthee CA, Cockcroft AC, Gopal K, Von Der Heyden S (2007) Mitochondrial DNA variation of the west-coast rock lobster, Jasus lalandii: Marked genetic diversity differences among sampling sites. Marine and Freshwater Research, 58, 1130-1135.

Le Moan A, Gagnaire PA, Bonhomme F (2016) Parallel genetic divergence among coastal-marine ecotype pairs of European anchovy explained by differential introgression after secondary contact. Molecular Ecology, 25, 3187-3202.

Momigliano P, Jokinen H, Fraimout A, Florin A-B, Norkko A, Merilä J (2017) Extraordinarily rapid speciation in a marine fish. Proceedings of the National Academy of Sciences, 201615109.

Obbard DJ, MacLennan J, Kim KW, Rambaut A, O'Grady PM, Jiggins FM (2012) Estimating divergence dates and substitution rates in the drosophila phylogeny. Molecular Biology and Evolution, 29, 3459-3473.

Oksanen J, Blanchet F, Friendly M, Kindt R, Legendre P, McGlinn D, Minchin PR, O'Hara RB, Simpson GL, Solymos P, Stevens MHH, Szoecs E, Wagner H (2019) vegan: Community Ecology Package. R package version 2.5-6.

Olivieri I, Tonnabel J, Ronce O, Mignot A (2016) Why evolution matters for species conservation:

$$
\text { Perspectives from three case studies of plant metapopulations. Evolutionary Applications, 9, 196-211. }
$$

Van Oppen MJH, Peplow LM, Kininmonth S, Berkelmans R (2011) Historical and contemporary factors shape the population genetic structure of the broadcast spawning coral, Acropora millepora, on the Great

$$
\text { Barrier Reef. Molecular Ecology, no-no. }
$$

Ovenden JR (2013) Crinkles in connectivity: combining genetics and other types of biological data to estimate movement and interbreeding between populations. Marine and Freshwater Research, 64, 201.

Ovenden JR, Booth JD, Smolenski AJ (1997) Mitochondrial DNA phylogeny of red and green rock lobsters (genus Jasus). Marine and Freshwater Research, 48, 1131-1136.

Ovenden JR, Brasher DJ, White RWG (1992) Mitochondrial DNA analyses of the red rock lobster Jasus edwardsii supports an apparent absence of population subdivision throughout Australasia. Marine Biology, 112, 319-326.

Palero F, Lopes J, Abelló P, Macpherson E, Pascual M, Beaumont MA (2009) Rapid radiation in spiny lobsters (Palinurus spp) as revealed by classic and $A B C$ methods using mtDNA and microsatellite data. BMC Evolutionary Biology, 9, 263.

Pecl G, Frusher S, Gardner C, Haward M, Hobday A, Jennings S, Nursey-Bray M, Punt A, Revill H, van Putten I (2009) The east coast Tasmanian rock lobster fishery - vulnerability to climate change impacts and 
adaptation response options. Report to the Department of Climate Change, Australia.

Phillips BF (2013) Lobsters: Biology, Management, Aquaculture and Fisheries (BF Phillips, Ed,). Department of Environment \& Agriculture, Curtin University, Western Australia.

Pickrell JK, Pritchard JK (2012) Inference of Population Splits and Mixtures from Genome-Wide Allele Frequency Data. PLoS Genetics, 8, e1002967.

Pinheiro HT, Bernardi G, Thorrold, Simon R.Joyeux J-C, Macieira RM, Gasparini JL, Rocha C, Rocha LA (2017) Island biogeography of marine organisms. Nature, 549, 82-85.

Pollock DE (1990) Palaeoceanography and Speciation in the Spiny Lobster Genus Jasus. Bulletin of Marine Science, 46, 387-405.

Porobić J, Canales-Aguirre CB, Ernst B, Galleguillos R, Hernández CE (2013) Biogeography and historical demography of the Juan Fernández rock lobster, Jasus frontalis (Milne Edwards, 1837). Journal of Heredity, 104, 223-233.

Rougemont Q, Bernatchez L (2018) The demographic history of Atlantic salmon (Salmo salar) across its

Rougeux C, Bernatchez L, Gagnaire PA (2017) Modeling the multiple facets of speciation-with-gene-flow

Sachs JP, Anderson RF (2005) Increased productivity in the subantarctic ocean during Heinrich events. Nature, 434.

Sakamoto Y, Ishiguro M, Kitagawa G (1986) Akaike Information Criterion Statistics. D. Reidel.

642 Sandoval-Castillo J, Robinson NA, Hart AM, Strain LWS, Beheregaray LB (2018) Seascape genomics reveals adaptive divergence in a connected and commercially important mollusc, the greenlip abalone (Haliotis laevigata), along a longitudinal environmental gradient. Molecular Ecology, 1603-1620.

Schaaf A (1996) Sea level changes, continental shelf morphology, and global paleoecological constraints in the shallow benthic realm: a theoretical approach. Palaeogeography, Palaeoclimatology, Palaeoecology, 121, 259-271.

Smadja CM, Butlin RK (2011) A framework for comparing processes of speciation in the presence of gene flow. Molecular Ecology, 20, 5123-5140.

Souissi A, Bonhomme F, Manchado M, Bahri-Sfar L, Gagnaire P-A (2018) Genomic and geographic footprints of differential introgression between two divergent fi sh species (Solea spp.). Heredity, 121, 579-593. 
652 Stanley JA, Hesse J, Hinojosa IA, Jeffs AG (2015) Inducers of settlement and moulting in post-larval spiny lobster. Oecologia, 178, 685-697.

654 Strugnell JM, Watts PC, Smith PJ, Allcock AL (2012) Persistent genetic signatures of historic climatic events in an Antarctic octopus. Molecular Ecology, 21, 2775-2787.

656 Thomas L, Bell JJ (2013) Testing the consistency of connectivity patterns for a widely dispersing marine species. Heredity, 111, 345-54.

Tine M, Kuhl H, Gagnaire P, Louro B, Desmarais E, Martins RST, Hecht J, Knaust F, Belkhir K, Klages S, Dieterich R, Stueber K, Piferrer F, Guinand B, Bierne N, Volckaert FAM, Bargelloni L, Power DM, Bonhomme F et al. (2014) European sea bass genome and its variation provide insights into adaptation to euryhalinity and speciation. Nature Communications, 5, 5770.

Titus BM, Blischak PD, Daly M (2019) Genomic signatures of sympatric speciation with historical and 665 Villacorta-Rath C, Ilyushkina I, Strugnell JM, Green BS, Murphy NP, Doyle SR, Hall NE, Robinson AJ, Bell JJ (2016) Outlier SNPs enable food traceability of the southern rock lobster, Jasus edwardsii. Marine Biology, 163, 1-11.

Villacorta-Rath C, Souza CA, Murphy NP, Green BS, Gardner C, Strugnell JM (2018) Temporal genetic patterns of diversity and structure evidence chaotic genetic patchiness in a spiny lobster. Molecular Ecology, 27, $54-65$.

Webber WR, Booth JD (1995) A new species of Jasus (Crustacea: Decapoda: Palinuridae) from the eastern South Pacific Ocean. New Zealand Journal of Marine and Freshwater Research, 29, 613-622. 